\title{
Re-evaluation of Seed Transmission of Clavibacter michiganensis subsp. nebraskensis in Zea mays
}

Charles C. Block, ${ }^{\dagger}$ Seed Science Center, Iowa State University, Ames, IA 50011; Lisa M. Shepherd, Seed Science Center, Iowa State University, Ames, IA 50011 (deceased); Gladys C. Mbofung-Curtis, Department of Plant Pathology and Microbiology, Iowa State University, Ames, IA 50011; Jeff M. Sernett, Monsanto Company, Huxley, IA 50124; and Alison E. Robertson, Department of Plant Pathology and Microbiology, Iowa State University, Ames, IA 50011

\begin{abstract}
The spread of Goss's bacterial wilt and leaf blight of corn (Zea mays), caused by Clavibacter michiganensis subsp. nebraskensis, to a wider geographic range in the early 2000s compared with the late 1960s has generated concern about the possible role of seed transmission in longdistance spread. The objectives of this research were: (1) to determine the percentage of seed infection found in seed harvested from inoculated and noninoculated plants of hybrids that varied in resistance to Goss's wilt; and (2) to estimate the seed transmission rate from these infected seed lots. The greatest percent seed infection was detected in seed from inoculated plants of the most susceptible hybrid and the least in seed from the most resistant hybrid. Seed lots with seed infection that ranged from 3.6 to $37.0 \%$ were planted in three field and three greenhouse trials. A total of 12 seed transmission events (Goss's wilt symptomatic seedlings) were identified among 241,850 plants

examined, for a seed transmission rate of $0.005 \%$. When the seed transmission rate was recalculated to consider only the infected seed portion of each seed lot, the rate increased to $0.040 \%$ (12 events from 30,088 potentially infected plants). Based on the low seed transmission rate observed and previous research on disease spread from a point source, it seems unlikely that seed transmission could introduce enough inoculum to create a serious disease outbreak in a single growing season. However, risk of seed transmission is relevant for phytosanitary restrictions and preventing the introduction of the pathogen to new areas. To date, Goss's wilt has not been detected outside North America, and while the risk of seed transmission is very low, the risk is not zero. Fortunately, the presence of $C$. michiganensis subsp. nebraskensis in corn seed is readily detectable by established seed health testing methods.
\end{abstract}

Goss's bacterial wilt and leaf blight of maize (Zea mays L.), hereafter referred to as Goss's wilt, caused by the bacterium Clavibacter michiganensis subsp. nebraskensis was originally discovered in south-central Nebraska in 1969 (Schuster 1972; Wysong et al. 1973). The geographic distribution of Goss's wilt remained localized in Nebraska and Colorado until the mid- to late 2000s when the disease became more widespread across the Corn Belt, moving east as far as Indiana (Ruhl et al. 2009), and north into Minnesota and North Dakota (Friskop et al. 2014; Malvick et al. 2010). Goss's wilt has been reported in the provinces of Manitoba and Alberta, Canada (Desjardins 2010; Howard et al. 2015), and as far south as Texas and Louisiana (Korus et al. 2011; Singh et al. 2015). The widespread distribution of Goss's wilt has been associated with increased corn-after-corn planting, reduced tillage that leaves more crop residue on the soil surface, increased rainfall, high-yielding and susceptible cultivars, and possibly seed transmission (Langemeier et al. 2017; Singh et al. 2015). To date, Goss's wilt has only been reported in North America, and many countries require a phytosanitary certificate for corn seed originating from the United States.

Goss's wilt leaf symptoms are characterized by long, wavy, water-soaked lesions with necrosis often most severe along the leaf margins (Jackson et al. 2007). The lesions frequently coalesce, causing a scorched appearance and eventual leaf death. Younger lesions often have a visible sheen of bacterial ooze or exudate on the underside of the leaf, which is most noticeable early in the morning. The most useful diagnostic symptom is the presence of dark-green or black water-soaked spots, referred to as freckles, within the

${ }^{\dagger}$ Corresponding author: C. C. Block, E-mail: ccblock@iastate.edu

*The $\boldsymbol{e}$-Xtra logo stands for "electronic extra" and indicates that one supplementary table is published online.

Accepted for publication 7 July 2018.

() 2019 The American Phytopathological Society lesions (Jackson et al. 2007). The pathogen can move systemically in the xylem of susceptible plants, leading to seed infection, wilting, and plant death (Jackson et al. 2007). C. michiganensis subsp. nebraskensis predominantly invades through wounds caused by wind, hailstorms, or wind-blown sand (Jackson et al. 2007). No insects are known to be associated with the spread of the pathogen. Yield losses associated with the disease can be severe, 30 to $50 \%$ and more, depending on hybrid susceptibility and on how early disease develops in the crop (Jackson et al. 2007; Wysong et al. 1973, 1981).

The primary inoculum source for C. michiganensis subsp. nebraskensis is infested crop residue on the soil surface (Gross and Vidaver 1979; Jackson et al. 2007; Schuster 1975; Smidt and Vidaver 1986). The pathogen overwinters in all plant parts including roots, stems, and leaves. On young plants, the pathogen has been shown to grow epiphytically and to multiply to at least $10^{7} \mathrm{CFU} \mathrm{g}{ }^{-1}$ fresh weight without symptom development (Eggenberger et al. 2016). Smidt and Vidaver (1986) associated symptom onset with bacterial populations that exceeded $10^{7} \mathrm{CFU} \mathrm{g}^{-1}$ fresh weight. Several grassy weeds that are common in corn fields have been shown to be susceptible and could serve as alternative hosts, including shattercane (Sorghum vulgare), foxtail (Setaria spp.), barnyardgrass (Echinochloa crus-galli), annual ryegrass (Lolium multiflorum), Johnsongrass (Sorghum halepense), and large crabgrass (Digitaria sanguinalis) (CABI 2018; Ikley et al. 2015; Langemeier et al. 2014). Seed transmission was suggested as the probable initial inoculum source when Goss's wilt was confirmed for the first time in Louisiana in 2013 (Singh et al. 2015), but the role of seed transmission in disease spread is not well established.

Biddle et al. (1990) demonstrated seed infection on parent plants in a field experiment in which a susceptible corn hybrid was inoculated with the $C$. michiganensis subsp. nebraskensis pathogen at various crop development stages. More severe blighting of the ear leaf corresponded with greater numbers of $C$. michiganensis subsp. nebraskensis colonies detected in both the exterior and interior of the seed collected from inoculated plants. Schuster (1975) detected C. michiganensis subsp. nebraskensis contamination in 126 of 399 ears collected from Goss's wilt symptomatic plants in five commercial 
cornfields in Nebraska, and seed infection averaged 20.8\%. Similarly, up to $32 \%$ of ears harvested from infested fields in Nebraska were shown to carry the bacterium on the seed (Jackson et al. 2007). Besides superficial contamination of the seed coat, C. michiganensis subsp. nebraskensis has been found in the interior of infected seeds, between the scutellum and the endosperm, and in the chalazal region (base) (Schuster 1975). The pattern of seed colonization is suggestive of the Stewart's bacterial wilt pathogen, Pantoea stewartii subsp. stewartii, which has also been isolated from the endosperm and chalazal region of infected corn seeds (Ivanoff 1933; Rand and Cash 1933). Histological studies have shown that the embryo is separated from the chalazal region and endosperm by several layers of cells (Ivanoff 1933; Rand and Cash 1933). Block et al. (1999) related Stewart's bacterial wilt foliar disease severity on the ear leaf of corn to seed infection by $P$. stewartii subsp. stewartii and suggested a threshold of 15 to $25 \%$ foliar disease severity was needed before infected seed was detected.

Seed transmission of $C$. michiganensis subsp. nebraskensis has not been studied extensively but is generally thought to be uncommon. Schuster (1975) reported that $C$. michiganensis subsp. nebraskensis was transmitted from seed to seedlings at the rate of $1.6 \%$ (30 of 1,934 plants) under greenhouse conditions, and found no seed transmission in a follow-up field planting of 300 seeds. The seed in that study came from C. michiganensis subsp. nebraskensis-infected ears collected from commercial cornfields. Biddle et al. (1990) did not observe seed transmission from 9,000 naturally infected seeds (17.1-30.7\% C. michiganensis subsp. nebraskensis-infected seeds) planted in the greenhouse or from 3,000 seeds from the same sources in a field planting. However, Biddle et al. (1990) did observe seed transmission in greenhouse plantings of vacuum-infiltrated seeds, and reported transmission rates of $0.1 \%$ from each of two 1,000 -seed plantings of one seed lot (70\% C. michiganensis subsp. nebraskensisinfected seeds) and 0.1 and $0.4 \%$, respectively, from two 1,000seed plantings of a second seed lot $(73 \%$ C. michiganensis subsp. nebraskensis-infected seeds). Shepherd (1999) reported a seed transmission rate of $0.04 \%$ (one of 2,568 plants) in a greenhouse planting from a naturally infected seed lot with $29 \%$ C. michiganensis subsp. nebraskensis-infected seeds, and no seed transmission among 1,421 plants of a second naturally infected seed lot with $3 \%$ infected seeds. In all of the above studies, relatively small amounts of seed $(<12,000$ seed) were tested.

Concerns about the role of seed transmission in the spread of Goss's wilt have increased in recent years due to the expansion of Goss's wilt and leaf blight into more of the corn growing regions of North America. Moreover, when the disease was observed in a new geographic area, it often occurred as circular areas of infected plants that seemed to radiate from a central point, suggesting infected seed as point sources of inoculum. Eggenberger et al. (2016) suggested that what seemed to be sudden outbreaks of the disease more likely resulted from gradual, nondetected buildup of inoculum on crop residue from susceptible hybrids grown in a continuous corn system for more than one growing season, rather than spread from point sources in a single season.

The goal of this study was to re-evaluate the seed transmission rate of $C$. michiganensis subsp. nebraskensis. Because seed transmission can be difficult to detect from seed lots in which a low percentage of seeds are infected, a 2012 field trial was established in Iowa in an attempt to produce seed lots with more than 50,000 seed each that varied in percentage of seed infection. Secondly, because seed infection may depend on disease severity on the parent plants (Biddle et al. 1990; Block et al. 1999), corn hybrids that varied in resistance to Goss's wilt were either inoculated or not inoculated in the field trial. Thus, the two objectives of this research were to: (1) assess the percentage of $C$. michiganensis subsp. nebraskensis infection found in seed harvested from noninoculated and inoculated plants of C. michiganensis subsp. nebraskensis-resistant, -susceptible, and -moderately resistant (MR) hybrids; and (2) to estimate the seed transmission rate from these infected seed lots. A re-evaluation of the seed transmission rate of $C$. michiganensis subsp. nebraskensis would improve our understanding of the epidemiology of this economically important pathosystem, specifically the potential role of seed transmission in the wider geographic area where Goss's wilt has been reported since the early 2000 s.

\section{Materials and Methods}

Seed lot production in the field. Four yellow dent corn hybrids that differed in resistance to Goss's wilt were obtained from Monsanto (Huxley, IA): DKC56-55, resistant, rated 2 on a 1 to 9 scale, ( 1 is excellent and 9 is poor); DKC61-16 and DKC59-35, rated 4 and 5, respectively, and therefore moderately resistant; and DKC55-09, rated 7 and susceptible. All four hybrids were planted on 19 May 2012 in a field plot with no prior history of Goss's wilt at Gilbert, IA. The seeding rate was approximately 94,000 plants per hectare. Each experimental unit consisted of a four-row plot, $17 \mathrm{~m}$ long by $3 \mathrm{~m}$ wide. The experimental design was a $4 \times 2$ (hybrid $\times$ inoculation treatment) factorial experiment in a randomized complete block with four replications arranged in a strip-split plot layout. Inoculated and noninoculated plots of the same hybrid were placed contiguously in the strip plots. Whole plants were inoculated at the V6 crop developmental stage (Abendroth et al. 2011) on 6 June with a mobile inoculation system (Hartsook et al. 2015). Briefly, the plants were sprayed with a grit medium to cause wounding, and then sprayed with a suspension of $C$. michiganensis subsp. nebraskensis (approximately $10^{8} \mathrm{CFU}$ per ml). Goss's leaf blight severity in each plot was assessed at 14-day intervals with the final assessment made 70 days after inoculation (DAI). Blight severity (percent symptomatic leaf area) was visually assessed on 10 plants at each of eight arbitrary stops within the middle two rows of each 4-row plot, for a total of 80 plants rated per plot. Grain was harvested from the middle two rows of each plot on 26 September using a plot combine (model MF 205; Massey Ferguson Ltd., Hesston, KS). The seed from each plot was dried at 32 to $34^{\circ} \mathrm{C}$ until it reached $11 \%$ moisture and then stored at $4{ }^{\circ} \mathrm{C}$ until seed infection and transmission could be evaluated.

The effects of hybrid and inoculation on leaf blight severity were analyzed using PROC GLIMMIX of SAS software (version 9.3, SAS Institute, Cary, NC), in which hybrid and inoculation were considered random effects. Mean comparisons were performed using Tukey's test at $P=0.05$ significance level.

Seed infection assay. The percentage of seeds from each field plot carrying viable $C$. michiganensis subsp. nebraskensis bacteria was determined by plating whole seeds onto semiselective sCNS agar medium (Shepherd 1999; Shepherd et al. 2017). The sCNS agar medium is a modification of CNS agar (Gross and Vidaver 1979), which stands for Corynebacterium nebraskense selective, with sCNS being less restrictive and optimized for extraction from seed. For each hybrid, there were eight seed lots, four replicates from inoculated plots, and four replicates from noninoculated plots. One hundred seeds were tested from each field plot in two replicates of 50 seed each, thus 400 seeds per hybrid $\times$ inoculation combination. The seeds were soaked for $90 \mathrm{~s}$ in $0.5 \%$ sodium hypochlorite with Tween 20 added at two drops per liter, placed in a sieve and thoroughly washed with deionized water, and then placed between sterile paper towels on the lab bench to dry. Seeds were plated with the tip cap down (standing upright) onto slightly soft (1.2\% agar) sCNS agar at 10 seeds per plate and incubated at 27 to $28^{\circ} \mathrm{C}$. Plating seeds with the tip cap embedded in the agar gave a higher percentage of $C$. michiganensis subsp. nebraskensis recovery compared with plating with the embryo side down or reverse side down. After 40 to $48 \mathrm{~h}$, the plates were inverted and the seeds were tapped off the agar. Plates were then returned to the incubator for 10 to 12 days to allow adequate time for $C$. michiganensis subsp. nebraskensis colony growth. C. michiganensis subsp. nebraskensis is slow-growing and not typically visible on sCNS agar until day 5 (Shepherd 1999). Colonies that were visible within the first 2 or 3 days never tested positive for C. michiganensis subsp. nebraskensis. Confirmation of $C$. michiganensis subsp. nebraskensis suspect colonies was done by pathogenicity testing according to method $\mathrm{Mz} 9.1$ of the National Seed Health System (http://seedhealth. org/). Briefly, for each suspected positive colony (round, raised, and 
peach-colored with a smooth margin), a loopful of the colony was mixed in a $1.5 \mathrm{ml}$ microtube of $0.02 \mathrm{M}$ phosphate buffered saline (PBS) to a concentration of $\sim 10^{8} \mathrm{CFU}$ per ml. One milliliter of the suspension was injected into a single 10- to 14-day-old corn seedling of a susceptible corn inbred (Mt42 or T220) using a 26 gauge tuberculin syringe. Each plant was injected at several points along the lower stem, 2.5 to $4 \mathrm{~cm}$ above the soil line, and incubated in a growth chamber at $27^{\circ} \mathrm{C}$ by day $22^{\circ} \mathrm{C}$ by night with a 15 -h photoperiod. Control plants were injected with $1 \mathrm{ml}$ of PBS. A seed was designated positive for seed infection by $C$. michiganensis subsp. nebraskensis if the inoculated plant developed characteristic symptoms of Goss's wilt (freckles, leaf lesions, wilting). Leaf freckles are a highly distinctive symptom, and no other maize pathogen produces them. Leaf freckles were always present on plants that tested positive for C. michiganensis subsp. nebraskensis and never observed on plants that tested negative. Periodic reisolations were made to save C. michiganensis subsp. nebraskensis cultures. Negative colonies (no plant infection observed) were retested by a second plant inoculation to verify the previous results. The percent seed infection for each seed lot was calculated as the number of seeds $(n=100)$ from which C. michiganensis subsp. nebraskensis was recovered.

Seed transmission studies. The three hybrid-by-inoculation treatment combinations that produced the highest percent seed infection were selected for seed transmission studies. Seeds from all four replicates of each hybrid-by-inoculation treatment were combined to create three large seed lots: (1) seed lot G1, seed harvested from the noninoculated plots of the susceptible hybrid DKC55-09; (2) seed lot G2, seed harvested from the inoculated plots of the susceptible hybrid DKC55-09; and (3) seed lot G3, seed harvested from the inoculated plots of the MR hybrid DKC59-35. Each seed lot was further divided into two sublots, A and B, by passing the seed over a laboratory air-screen cleaner (model LA-LS, Westrup A/S, Slagelse, Denmark) to concentrate the small and lighter seeds into the B fraction. The presumption was that small and lighter seeds were more likely to be infected and stunted by $C$. michiganensis subsp. nebraskensis, which in turn could affect seedling emergence and/or seed transmission of $C$. michiganensis subsp. nebraskensis. Two hundred seeds from each seed sublot (G1-A, G1-B, G2-A, G2-B, G3-A, and G3-B) were then tested by agar plating, in the same manner as previously described, to determine the percentage of $C$. michiganensis subsp. nebraskensis-infected seeds in each sublot. Warm germination tests were also conducted with 400 seeds at the Iowa State University Seed Science Center using standard procedures (Association of Official Seed Analysts 2011). Briefly, 400 seeds from each fraction were planted on crepe cellulose paper (Versa-Pak, Seedburo Equipment Co., Des Plaines, IL) and placed at $25^{\circ} \mathrm{C}$ for 7 days when percent germination was evaluated.

Seed from each seed sublot was planted in a field at Ames, IA with no previous history of Goss's wilt. On 8 June 2013, seeds from sublots G1-A (43,900 seeds), G1-B (3,300 seeds), G2-A (48,500 seeds), G2-B (15,600 seeds), G3-A (40,200 seeds), and G3-B (4,900 seeds) were planted in one grow-out trial. An attempt was made to plant seed numbers from each sublot in proportion to their representation in the original parent lot. For example, parent lot G1 was split into G1-A (93.0\% of the seeds) and G1-B (6.5\%), thus 43,900 of the 47,200 seeds (93.0\%) planted between G1-A and G1-B came from the G1-A fraction. A second grow-out trial was planted on 15 July 2013, with 22900, 29400, and 21100 seeds representing parent seed lots G1, G2, and G3, respectively. Each seed lot was planted in a block with the A and B sublots planted side-by-side. Stand counts were made 10 to 12 days after emergence.

All blocks were scouted weekly from emergence through tasseling to determine if a seed transmission event of C. michiganensis subsp. nebraskensis had occurred. That is, all plants were visually inspected for symptoms of Goss's wilt, specifically chlorotic or necrotic lesions on the leaves, water-soaking, leaf freckles, or whole plant wilting. Suspected Goss's wilt symptomatic plants were tested initially with immunostrips (Agdia Inc., Elkhart, IN) designed for C. michiganensis subsp. michiganensis, the tomato canker pathogen. The immunostrips cross-react with $C$. michiganensis subsp. nebraskensis (Korus
2011); thus a positive strip test was considered only as a presumptive positive test for $C$. michiganensis subsp. nebraskensis. Suspected positive plants were removed from the field and used for bacterial isolations by dilution plating, pathogenicity testing, and completion of Koch's postulates. All plants that showed necrotic leaf streaks (no leaf freckles) or wilting and that tested negative by the immunostrip test were still advanced to agar plating, but these plants were never positive for $C$. michiganensis subsp. nebraskensis. Field locations where symptomatic plants were found were flagged so that neighboring plants could be monitored for natural disease spread.

In addition to the three field trials, a total of 8,250 seed from seed lot G2-A (18.4\% C. michiganensis subsp. nebraskensis-infected seed) were planted in greenhouse grow-out trials on 8 July, 5 August, and 30 August 2013. Seeds were planted in Sungrow Sunshine Mix \#1 (Sun Gro Horticulture, Agawam, MA) in \#7 Short Poly-Tainer pots (Hummert Intl., Earth City, MO) at 50 seeds per pot. Plants were observed for symptoms of Goss's wilt-infected plants until the V5 growth stage when they became too large to maintain.

In 2014, all remaining seed from the six 2013 seed lots (G1-A, G1B, G2-A, G2-B, G3-A, and G3-B) were combined into a single seed lot (36,900 seed), and planted on 11 June in a third grow-out field trial. The percentage of seeds carrying viable $C$. michiganensis subsp. nebraskensis bacteria was retested by plating 200 seeds on sCNS agar in the same manner as previously described, resulting in a $9.0 \%$ infected seed lot.

Calculation of seed transmission rates. The seed transmission rates from each planting were initially calculated as the number of seed transmission events observed (infected plants) divided by total plants. However, the use of total plant numbers did not account for the differences in C. michiganensis subsp. nebraskensis seed infection levels among seed lots, such as the $3.6 \%$ seed infection in lot G3-B compared with the $37 \%$ seed infection in lot G2-B. A more conservative approach was used to calculate adjusted transmission rates from only the potentially Goss-positive plants, i.e., the proportion of plants estimated to have grown from infected seeds. This approach more accurately reflected the actual frequency of seed transmission. A one-sided $95 \%$ upper confidence limit was calculated for each seed lot using SeedCalc3 software (ISTA, www.seedtest.org). The upper confidence limit provided a means of assessing the reliability of a seed transmission estimate when a limited number of plants were tested (Block et al. 1998; Couey and Chew 1986). With more plants tested, the precision of the estimate improved and the upper confidence limit dropped to approach the observed transmission rate. The adjusted seed transmission rate and the upper confidence limit were used to estimate the maximum number of infected plants one could expect to find in a field.

\section{Results}

Seed lot production and percent seed infection. Goss's wilt leaf blight was observed in both the inoculated and noninoculated plots of the field trial as the pathogen spread from inoculated plots to neighboring noninoculated plots. Mean Goss's leaf blight severity at 70 DAI among the inoculated plots ranged from $1.6 \%$ in the resistant hybrid DKC56-55, 87.9\% in the susceptible hybrid DKC55-09, and from 1.2 to $26.7 \%$ for noninoculated resistant and susceptible hybrids, respectively (Table 1). Despite Goss's wilt leaf blight occurring in every field plot, seed infection was not detected in every plot. Seed infected with $C$. michiganensis subsp. nebraskensis was, however, found in at least one of the four replicate plots of every hybrid-by-inoculation treatment combination (Table 1). Seed infection was greatest in seed lots of the susceptible hybrid DKC55-09, an average of $21.4 \pm 4.0 \%$ seed infection from the inoculated plots and $5.1 \pm 2.2 \%$ seed infection from the noninoculated plots (Table 1). Seed infection in the resistant hybrid DKC56-55 was significantly lower, with an average of $2.5 \pm 1.5 \%$ seed infection from the inoculated plots and $0.8 \pm 0.8 \%$ seed infection from the noninoculated plots. Moreover, infected seed were detected in three of the four replicate plots of the inoculated resistant hybrid and two of the four replicate noninoculated plots of the same hybrid (Table 1). For the two MR hybrids, DKC61-16 and DKC59-35, the inoculated 
plots averaged $3.3 \pm 1.8 \%$ and $6.0 \pm 2.3 \%$ seed infection, respectively. For both MR hybrids, infected seeds were detected in three of the four inoculated replicate plots. The corresponding noninoculated plots of the MR hybrids averaged $1.3 \pm 1.1 \%$ and $1.0 \pm 0.9 \%$ seed infection, respectively (Table 1). However, all of the infected seeds were found in only one of the four noninoculated replicate plots for both MR hybrids, with 5\% seed infection in one replicate plot of DKC61-66 and 4\% seed infection in one replicate plot of DKC59-35. Overall, from the 32 field plots with 100 seed tested per plot, a total of 180 C. michiganensis subsp. nebraskensis-positive colonies were confirmed from 330 suspect colonies tested. These numbers are reflected in the seed infection percentages shown in Table 1.

Seed transmission results. In the June 2013 field grow-out, 11 C. michiganensis subsp. nebraskensis-infected plants (seed transmission events) were confirmed among 135,950 plants, an overall seed transmission rate of $0.0081 \%$ (Table 2). Seed infection percentages for sublots planted in this trial ranged from 3.6 to $37.0 \%$ (Table 2), and the number of potentially infected plants, i.e., plants in the field estimated to have grown from an infected seed, totaled 17,620 plants. When the seed transmission rate was normalized to consider only the infected seeds planted (potentially Goss-positive plants), the adjusted seed transmission rate was $0.062 \%$. Seed transmission was detected in three of the six sublots G2-A (6 events), G2B (3 events), and G3-A ( 2 events). The observed seed transmission rates in these three sublots were $0.016,0.024$, and $0.006 \%$, respectively (Table 2), and when normalized to adjust for infected seeds, the adjusted transmission rates were $0.084,0.065$, and $0.079 \%$, for G2-A, G2-B, and G3-A, respectively (Table 2).

No seed transmission events were found among 60,750 plants in the July 2013 field grow-out trial, although the same seed lots were planted and in the same proportions of A and B sublots as for the June 2013 field trial (Table 2). The weather in July 2013 was hot (32 to $35^{\circ} \mathrm{C}$ day) and dry, and overall emergence was slightly lower $(82.7 \%)$ than that observed for the June 2013 planting (86.9\%). Similarly, no seed transmission events were observed from 36,900 plants in the 2014 field grow-out trial (Table 2), which was a bulk mixture

Table 1. Single-seed assays to estimate the incidence of seed infected with Clavibacter michiganensis subsp. nebraskensis harvested from inoculated and noninoculated plots of each of four maize hybrids of varying resistance

\begin{tabular}{|c|c|c|c|c|}
\hline Hybrid/resistance $^{w}$ & $\begin{array}{c}\text { Field } \\
\text { inoculation }\end{array}$ & $\begin{array}{l}\text { Final foliar disease severity } \\
(\%) \text { at } 70 \text { days after inoculation }\end{array}$ & $\begin{array}{l}\text { No. of reps with } \\
\text { infected seeds }\end{array}$ & $\begin{array}{c}\text { Average percent infected seeds } \pm 95 \% \\
\text { confidence interval }\end{array}$ \\
\hline DKC55-09 (S) & $\mathrm{NO}$ & $26.7 \mathrm{~b}$ & 4 of 4 & $5.1 \pm 2.2^{z}$ \\
\hline DKC55-09 (S) & YES & $87.9 \mathrm{a}$ & 4 of 4 & $21.4 \pm 4.0^{z}$ \\
\hline DKC59-35 (MR) & NO & $5.1 \mathrm{~d}$ & 1 of 4 & $1.0 \pm 0.9$ \\
\hline DKC59-35 (MR) & YES & $31.4 \mathrm{~b}$ & 3 of 4 & $6.0 \pm 2.3^{z}$ \\
\hline DKC61-16 (MR) & NO & $6.3 \mathrm{~d}$ & 1 of 4 & $1.3 \pm 1.1$ \\
\hline DKC61-16 (MR) & YES & $17.8 \mathrm{c}$ & 3 of 4 & $3.3 \pm 1.8$ \\
\hline DKC56-55 (R) & NO & $1.2 \mathrm{~d}$ & 2 of 4 & $0.8 \pm 0.8$ \\
\hline DKC 56-55 (R) & YES & $1.6 \mathrm{~d}$ & 3 of 4 & $2.5 \pm 1.5$ \\
\hline
\end{tabular}

${ }^{\mathrm{w}} \mathrm{S}=$ susceptible hybrid, $\mathrm{R}=$ resistant hybrid, $\mathrm{MR}=$ moderately resistant to Goss's wilt and leaf blight.

x Letters indicate significant differences in leaf disease severity based on Tukey's test $(P<0.05)$.

y 400 Seeds were tested per treatment combination (hybrid $x$ inoculation), 100 seeds per plot with four replicate plots.

${ }^{\mathrm{z}}$ Seeds from the four replications of this treatment were blended for use in seed transmission grow-outs.

Table 2. Seed-to-seedling transmission of Clavibacter michiganensis subsp. nebraskensis (Cmn) from infected maize seed

\begin{tabular}{|c|c|c|c|c|c|c|c|c|}
\hline Grow-out trials & Seed lot ${ }^{\mathbf{u}}$ & $\begin{array}{l}\text { Mean } C m n \text { seed } \\
\text { infection }(\%)^{\mathrm{v}}\end{array}$ & $\begin{array}{l}\text { Total number } \\
\text { of plants }\end{array}$ & $\begin{array}{c}\text { Potential } \\
\text { Goss-infected } \\
\text { plants }^{\mathbf{w}}\end{array}$ & $\begin{array}{c}\text { \# Seed } \\
\text { transmission } \\
\text { events }\end{array}$ & $\begin{array}{c}\text { Overall seed } \\
\text { transmission } \\
\text { rate }(\%)^{\mathbf{x}}\end{array}$ & $\begin{array}{c}\text { Adjusted seed } \\
\text { transmission } \\
\text { rate }(\%)^{\mathbf{y}}\end{array}$ & $\begin{array}{l}\text { 95\% Upper } \\
\text { confidence } \\
\text { limit }^{\mathrm{z}}\end{array}$ \\
\hline \multirow[t]{6}{*}{ Field (June 2013) } & G1-A & 7.0 & 41,400 & 2,898 & 0 & 0.000 & 0.000 & 0.103 \\
\hline & G1-B & 11.5 & 2,900 & 334 & 0 & 0.000 & 0.000 & 0.890 \\
\hline & G2-A & 18.4 & 38,600 & 7,102 & 6 & 0.016 & 0.084 & 0.167 \\
\hline & G2-B & 37.0 & 12,400 & 4,588 & 3 & 0.024 & 0.065 & 0.169 \\
\hline & G3-A & 7.0 & 36,300 & 2,541 & 2 & 0.006 & 0.079 & 0.248 \\
\hline & G3-B & 3.6 & 4,350 & 157 & 0 & 0.000 & 0.000 & 1.890 \\
\hline Total & & & 135,950 & 17,620 & 11 & 0.008 & 0.062 & 0.103 \\
\hline \multirow[t]{6}{*}{ Field (July 2013) } & G1-A & 7.0 & 18,200 & 1,274 & 0 & 0.000 & 0.000 & 0.235 \\
\hline & G1-B & 11.5 & 750 & 86 & 0 & 0.000 & 0.000 & 3.423 \\
\hline & $\mathrm{G} 2-\mathrm{A}$ & 18.4 & 17,900 & 3,294 & 0 & 0.000 & 0.000 & 0.091 \\
\hline & G2-B & 37.0 & 4,600 & 1,702 & 0 & 0.000 & 0.000 & 0.176 \\
\hline & G3-A & 7.0 & 17,000 & 1,190 & 0 & 0.000 & 0.000 & 0.251 \\
\hline & G3-B & 3.6 & 2,300 & 83 & 0 & 0.000 & 0.000 & 3.545 \\
\hline Total & & & 60,750 & 7,629 & $\mathbf{0}$ & 0.000 & 0.000 & 0.039 \\
\hline Field (June 2014) & G123 bulk & 9.0 & 36,900 & 3,321 & 0 & 0.000 & 0.000 & 0.090 \\
\hline Field Total & & & 233,600 & 28,570 & 11 & 0.005 & 0.039 & 0.064 \\
\hline $\begin{array}{l}\text { Greenhouse (July and } \\
\text { Aug 2013) }\end{array}$ & G2-A & 18.4 & 8,250 & 1,518 & 1 & 0.012 & 0.066 & 0.312 \\
\hline Overall & & & 241,850 & 30,088 & 12 & 0.005 & 0.040 & 0.065 \\
\hline
\end{tabular}

u G1, seed harvested from plots of noninoculated DKC 55-09 (susceptible to Cmn); G2, seed harvested from plots of inoculated DKC 55-09; G3, seed harvested from plots of inoculated DKC 59-35 (moderately resistant to $\mathrm{Cmn}$ ). The seed was passed over a laboratory air-screen cleaner to separate the seed lot into two fractions, where the B fraction consisted of smaller, lighter seed.

v Percentage of seeds with viable Cmn cells was determined by plating seeds onto sCNS agar medium.

${ }^{w}$ Potential Goss-infected plants = total plant count multiplied by percentage of infected seeds in the seed lot.

${ }^{x}$ Number of seed transmission events divided by total plants.

y Adjusted seed transmission rate $=$ seed transmission events divided by the potential Goss-infected plants.

z 95\% Upper confidence limit for the adjusted seed transmission rate. 
of all the remaining seed from the six seed lots planted in the 2013 field trials.

In all field trials, plants with yellow leaves, necrotic leaf streaks, and/or wilting were occasionally found from which C. michiganensis subsp. nebraskensis was not detected. These plants were dug up for further analysis in the laboratory. The symptoms were often characteristic of those caused by fungi such as Penicillium oxalicum or Fusarium spp., or to damage by insects such as cutworms and wireworms. This underscored the importance of not simply relying on wilt symptoms or necrotic streaks for diagnosis of Goss's wilt. Leaf freckles were always present when a plant tested positive for C. michiganensis subsp. nebraskensis, and freckles were never observed on plants that tested negative.

In the greenhouse grow-outs, seeds were planted from sublot G2-A with $18.4 \%$ seed infection. One seed transmission event was detected among the 8,250 plants, for an adjusted seed transmission rate of $0.066 \%$, which was close to the $0.084 \%$ detected for the same seed G2-A seed lot in the June 2013 field, and nearly identical to the overall June 2013 seed transmission rate of $0.062 \%$ (Table 2).

In total, 12 seed transmission events of $C$. michiganensis subsp. nebraskensis were identified from the three field (11 events) and three greenhouse grow-out trials ( 1 event). When the 12 seed transmission events were divided by the total number of plants grown $(241,850)$, an overall seed transmission rate of 0.000050 or $0.005 \%$ was obtained, which is equivalent to one seed transmission event per 20,000 plants. The adjusted seed transmission rate was estimated to be $0.040 \%$ (12 of 30,088 potentially infected plants) with a $95 \%$ upper confidence limit of $0.065 \%$ (Table 2). Thus, for a seed lot that consists entirely of infected seeds, the prediction would be that one seed transmission event would occur from every 2,500 seeds planted $(2,500 \times$ $0.00040=1$ plant $)$. Because no seed transmission was recorded in the July 2013 or the June 2014 field plantings, those 97,650 plants were temporarily excluded and the adjusted seed transmission rate was recalculated from only the June 2013 field data, which produced a modestly higher result at $0.062 \%$ (11 events from 17,620 potentially infected plants) and a $95 \%$ upper confidence limit of $0.103 \%$.

The seed transmission data generated in this study fit the general criteria for a Poisson distribution in which events are rare, random, and occur independently (Ott 1988; Steel and Torrie 1980). The Poisson distribution provides an approximation of the binomial distribution where the proportion $(p)$ of seed transmission events is small, e.g., from 0.0001 to 0.01 , and the number $(n)$ of trials, i.e., plants, is large (Ott 1988; Steel and Torrie 1980). The expected number of seed transmission events $(\mu)$ can be calculated by the equation $\mu=n p$ where $n$ is the total plant number and $p$ is the proportion of positives observed. Based on the overall seed transmission rate observed in this study $(p=0.00040)$, a hypothetical seed lot that contained $100 \%$ C. michiganensis subsp. nebraskensis-infected seeds would be expected to yield between 0 and 4 cases of seed transmission per 10,000 seedlings. For a seed lot with $1 \%$ infected seeds, the risk would be 100 times lower, between 0 and 4 infected plants per $1,000,000$ plants. Zero is included as a possibility because seed transmission was not observed in this study in both the July 2013 and the June 2014 field grow-out plantings. If the June 2013 transmission rate $(0.062 \%)$ was repeated in July 2013 and June 2014, two to three infected plants should have been found in July 2013 and one to two infected plants in the June 2014

In 2014, although field conditions seemed to be ideal for seed germination, with warm soil and good moisture available, no seed transmission events were detected. The seed was known to carry viable $C$. michiganensis subsp. nebraskensis bacteria, having been tested four times ( 400 seeds total) by agar plating in the 2 weeks before planting. With 36,900 plants and a $9 \%$ infected seed lot, there were 3,321 potentially infected plants in the field $(36,900 \times 0.09)$. Using the seed transmission rate of $0.040 \%(p=0.00040)$, at least one infected plant $(u)$ was expected, as calculated by the equation $\mu=n p(3,321 \times 0.00040=1.32)($ Ott 1988). Due to the relatively small plant population in the field, finding no infected plants was still a possibility. The probability $(P)$ of finding zero infected plants was therefore calculated using the Poisson equation, $P_{y}=u^{y} e^{-u} / y$ !, where $y$ is the expected number of seed transmission events (in this case 0$), e$ is the base of the natural logarithm (2.71828) and $\mu=n p$ (Ott 1988). With the transmission rate of $p=0.00040$ and $n=3,321$ plants, the probability of no seed transmission events $\left(P_{0}\right)$ was $26 \%$. Conversely, the probability $\left(1-P_{0}\right)$ of one or more seed transmission events was $74 \%$. If the June 2013 seed transmission rate of $0.062 \%$ was substituted into the equation, the probability of finding one or more seed transmission events in June 2014 increased to $87 \%$ and the probability of zero infected plants dropped to $13 \%$. By either estimate, there was a reasonably good chance of finding at least one infected plant. The fact that none was detected demonstrates that seed transmission is not a certainty.

\section{Discussion}

By planting four corn hybrids that varied in resistance to C. michiganensis subsp. nebraskensis, and either inoculating or not inoculating the plants with the pathogen at the V6 growth stage, a wide range of Goss's leaf blight severity was created and a wide range of seed infection levels was generated. As expected, the most severe disease rating occurred in the inoculated plots of the susceptible hybrid DKC55-09 (87.9\% leaf disease severity), and the least severe disease occurred in the noninoculated plots of the resistant hybrid DKC56-55 (1.2\% severity) (Table 1). The high leaf blight severity levels in the susceptible hybrid in both the inoculated $(87.9 \%$ severity) and noninoculated plots ( $26.7 \%$ severity) revealed how severe Goss's wilt disease could become in a susceptible hybrid. Similarly, seed infection was highest in the seed harvested from inoculated plots of the susceptible hybrid (21.4\% infected seed) and lowest in the seed harvested from noninoculated plots of the resistant hybrid $(0.8 \%$ infected seed).

The presence of infected seeds in seed lots harvested from plots with low levels of foliar disease on the seed parent plants was not expected. The initial premise was that seed infection by C. michiganensis subsp. nebraskensis would follow a pattern similar to that for $P$. stewartii subsp. stewartii, which causes Stewart's wilt of corn, where infected seed was detected only from systemically infected plants with $>25 \%$ leaf disease severity (Block et al. 1999). In the current study, however, infected seed was detected in seed harvested from plots that never reached 5\% leaf disease severity. For example, seed infection from two noninoculated replicate plots of the resistant hybrid DKC56-55 were 1.0 and $2.0 \%$, when the mean leaf disease severities at $70 \mathrm{DAI}$ in those plots were 2.8 and $0.5 \%$, respectively (Supplementary Table S1). Similarly, one replicate plot of the moderately resistant hybrid DKC59-35 had 4.0\% seed infection, and the most severe leaf disease recorded in that plot at 70 DAI was $4.1 \%$.

Because all plots were machine harvested, it is possible that seed harvested from each plot may have been affected by crosscontamination or carryover of seeds from one plot to another during harvest. Systemic infection of plants by $C$. michiganensis subsp. nebraskensis in the 2012 seed production plots was not assessed. It is not clear from published literature if systemic infection is required for seed infection of corn by C. michiganensis subsp. nebraskensis. The bacterium has been recovered from all plant parts including the husks and cobs (Schuster 1975). Future work on seed infection of corn by $C$. michiganensis subsp. nebraskensis should evaluate if the Goss's wilt pathogen has a different mechanism of seed colonization compared with the Stewart's wilt pathogen where systemic plant infection does seem to be required (Block et al. 1999). It should be mentioned that the seed used in the transmission studies was hybrid commercial corn seed and not seed from the inbred parent lines. Inbred lines are not as vigorous as the hybrids, and the relationship between seed infection levels and seed transmission rates might be different between inbreds and hybrids.

The adjusted transmission rate of $C$. michiganensis subsp. nebraskensis, $0.040 \%$ (12 infected seedlings detected from 30,088 potentially infected plants), was less than that reported by Shepherd (1999), who observed a seed transmission rate of $0.13 \%$ (one infected seedling from 745 potentially infected plants). However, that estimate (Shepherd 1999) was based on a small number of plants with a single seed 
transmission event, and the rate would have changed as more plants were tested. When seed transmission events are uncommon, the observed seed transmission rate tends to fluctuate considerably if a limited number of plants is screened (Block et al. 1998). For example, one infected plant might be found among the first 500 plants, and the second seed transmission event might not occur until 5,000 plants were grown. The observed transmission rate after 500 plants would be $0.2 \%$, and $0.04 \%$ after 5,000 plants. Hence, the estimated seed transmission rate becomes more stable with larger numbers of plants.

The adjusted seed transmission rate for C. michiganensis subsp. nebraskensis reported herein was very similar to the adjusted seed transmission rates observed for Stewart's wilt by both Block et al. (1998) and Michener et al. (2002). Michener et al. (2002) reported an average $P$. stewartii subsp. stewartii seed transmission rate of $0.038 \%$ (22 infected plants from 58,300 potentially infected plants). Block et al. (1998) reported seed transmission rates of $0.022 \%$ from naturally infected seeds (one infected plant from 4,563 potentially infected plants) and $0.14 \%$ from severely infected seed lots (37 to $72 \%$ P. stewartii-infected seeds), with 28 infected plants from 19,735 potentially infected plants. The rarity of seed transmission for these two bacterial pathogens of corn may point to similar physical locations for the Stewart's wilt and Goss's wilt bacteria in infected seeds and similar mechanisms of seed transmission. The trials were established with the assumption that infected and noninfected seeds would germinate equally well under favorable soil conditions. This was true for light $(0.7$ and $3.6 \%)$ and moderately infected $(27 \%)$ seed lots in a Stewart's wilt greenhouse study (Block 1996). The author showed that germination was not significantly affected by $P$. stewartii subsp. stewartii seed infection until infection percentages reached $40 \%$. Seed lots with $>40 \%$ $P$. stewartii subsp. stewartii infection had much greater proportions of small, light seeds that did not germinate. In the present study, the seed infection percentages for the seven seed lots were 3.6, 7.0, 7.0, $9.0,11.5,18.4$, and $37.0 \%$, with G2-B (37\%) as the most likely to contain a high proportion of small, light seeds.

The reason for the later (mid-July 2013) planting date was to plant into warm soil $\left(>18^{\circ} \mathrm{C}\right)$, with the idea that this method might promote maximum germination of poor quality seeds and increase the chances for seed transmission to occur. Although the seed lots used in this study had warm germination values between 85 and $98 \%$ in the laboratory (Table 3 ), neither a vigor test nor a cold test was conducted. Germination of these seed lots probably would have been lower under more stressful conditions than those observed in the warm germination test. The relatively low quality of some of the seed lots was demonstrated by their poor field emergence. For example, seed lot G2-B (37\% infected seed) had $85 \%$ germination in the warm germination test, $79.5 \%$ emergence in the June 2013 field planting and $63.9 \%$ emergence in the July 2013 field planting (Table 3). Similarly, seed lot G1-B (11.5\% infected seed and $90 \%$ warm germination) dropped from 88 to $68 \%$ emergence between the June and July plantings. One possible reason for poor emergence in July 2013 could be the weather conditions at planting, with daytime temperatures from 32 to $35^{\circ} \mathrm{C}$ and dry soils. Overall emergence across seed lots was slightly lower in July 2013 (82.7\%) compared with the June 2013 trial (86.9\%) (Table 3).

One surprising result was that seed transmission was not detected from either the G1-A (7\% infection) or G1-B (11.5\% infection) seed lots, even though the number of potentially infected plants $(4,592$ in total for both lots) was great enough to expect one or two seed transmission events. The G1-A and G1-B seed lots were composed of seed harvested from the noninoculated plots of the susceptible hybrid DKC55-09. Greater seed infection was found in the G2-A and G2-B seed lots, which were harvested from the inoculated plots of the same hybrid. Disease was slower to develop in the noninoculated plots of DKC55-09. At 28 DAI (V15 to V16 growth stage), Goss's wilt symptoms were present in just two of the four replicate plots, and only at $<5 \%$ leaf severity (data not shown). In contrast, Goss's leaf blight was observed in all four replicate inoculated plots of DKC55-09 as early as 14 DAI (data not shown). Leaf disease severity in the inoculated plots of DKC55-09 at 70 DAI was $87.9 \%$ compared with $26.7 \%$ in the noninoculated plots of the same hybrid. Similarly, seed infection in the inoculated plots of DKC55-09 was four-fold greater $(21.4 \%)$ than in the noninoculated plots $(5.1 \%)$. This suggests that the severity of seed infection and potential risk of seed transmission may be affected by plant growth stage at the time of infection and final disease severity.

This study screened about 10 times as many plants $(241,850$ plants) as all previous $C$. michiganensis subsp. nebraskensis seed transmission studies combined (Biddle et al. 1990; Schuster 1975; Shepherd 1999) and was the first to attach a confidence limit to the estimated seed transmission rates. The upper confidence limit provides a valuable tool to help evaluate risk of seed transmission. For example, a seed lot with $1 \%$ infected seeds planted at 82,500 seeds per hectare $(33,000$ per acre) would place 825 infected seeds in the soil per hectare. If the $95 \%$ upper confidence limit of $0.10 \%$ from the June 2013 field planting was applied, the maximum expected number of seed transmission events would be 0.825 , less than one event per hectare. The seed lots used in this study were useful for demonstrating seed transmission without planting millions of seed but were not representative of the highest quality commercial seed lots which are expected to have lower risk of Goss's wilt seed transmission. It seems reasonable to expect that quality seed lots would have lower risks of seed transmission than the seed lots used in this study.

Based on the rarity of seed transmission and the findings of Eggenberger et al. (2016) that showed that Goss's wilt spreads slowly from a point source, it seems unlikely that seed transmission could introduce enough inoculum to create a serious disease outbreak in a single growing season. Eggenberger et al. (2016) concluded that what seem to be sudden outbreaks of Goss's wilt probably resulted from a gradual, nondetected buildup of inoculum over more than one season. Disease foci observed in fields could result from windblown $C$. michiganensis subsp. nebraskensis-infested residue or pathogen spread during severe thunderstorms as much as from seed transmission. The risk of seed transmission is more relevant to phytosanitary issues, that is, introducing the pathogen into an area where Goss's wilt does not currently occur. Goss's wilt has not been detected outside North America, and while the likelihood of seed transmission is low from commercial seed lots, the risk is still more than zero when infected seeds are present in the seed lot. Thus, field inspections and seed health testing for the presence of $C$. michiganensis subsp. nebraskensis remain important phytosanitary measures for preventing potential disease spread. Fortunately, infected seed lots are relatively easy to detect by seed health testing, and an established

Table 3. Laboratory germination percentages and seedling emergence in field and greenhouse grow-out trials

\begin{tabular}{|c|c|c|c|c|c|}
\hline Seed lot & $\%$ Seed infection ${ }^{y}$ & $\%$ Warm germ $(\mathbf{l a b})^{\mathrm{z}}$ & \% Emergence June 2013 field & \% Emergence July 2013 field & \% Emergence 2013 greenhouse \\
\hline G1-A & 7.0 & 97.5 & 94.3 & 83.5 & Not grown \\
\hline G1-B & 11.5 & 90.3 & 87.9 & 68.2 & Not grown \\
\hline G2-A & 18.4 & 97.0 & 79.6 & 80.6 & $93.3^{\circ}$ \\
\hline G2-B & 37.0 & 85.0 & 79.5 & 63.9 & Not grown \\
\hline G3-A & 7.0 & 96.5 & 90.3 & 90.9 & Not grown \\
\hline G3-B & 3.6 & 93.0 & 88.8 & 95.8 & Not grown \\
\hline
\end{tabular}

\footnotetext{
y Two hundred seeds were tested per seed lot by plating four replicates of 50 seeds onto sCNS agar.
}

${ }^{\mathrm{z}}$ Four replicates of 100 seed were tested using standard procedures (AOSA 2011). 
laboratory procedure is available (Shepherd et al. 2017). Vigilance through the phytosanitary activities of field inspection and seed health testing should be sufficient to prevent spread of Goss's wilt by seed transmission.

\section{Literature Cited}

Abendroth, L. J., Elmore, R. W., Boyer, M. J., and Marla, S. K. 2011. Corn growth and development. Iowa State Univ. Ext. Publ. PMR-1009.

Association of Official Seed Analysts. 2011. Rules for Testing Seeds. Association of Official Seed Analysts, Lincoln, NE.

Biddle, J. A., McGee, D. C., and Braun, E. J. 1990. Seed transmission of Clavibacter michiganense subsp. nebraskense in corn. Plant Dis. 74:908-911.

Block, C. C. 1996. Biology of seed transmission of Erwinia stewartii in maize. Ph. D. Diss. Iowa State University, Ames, IA.

Block, C. C., Hill, J. H., and McGee, D. C. 1998. Seed transmission of Pantoea stewartii in field and sweet corn. Plant Dis. 82:775-780.

Block, C. C., Hill, J. H., and McGee, D. C. 1999. Relationship between late-season severity of Stewart's bacterial wilt and seed infection in maize. Plant Dis. 83: $527-530$.

Couey, H. M., and Chew, V. 1986. Confidence limits and sample size in quarantine research. J. Econ. Ent. 79:887-890.

CABI. 2018. Clavibacter michiganensis subsp. nebraskensis (Goss's bacterial wilt \& leaf blight). In: Crop Protection Compendium. CAB International, Wallingford, U.K. www.cabi.org/cpc.

Desjardins, M. L. 2010. 2009 Manitoba Crop Diagnostic Centre laboratory submissions. pp. 20-27. Can. Plant Dis. Surv. 90:1-166.

Eggenberger, S., Diaz Arias, M. M., Gougherty, A. V., Nutter, F. W., Sernett, J., and Robertson, A. E. 2016. Dissemination of Goss's wilt of maize and epiphytic Clavibacter michiganensis subsp. nebraskensis from inoculum point sources. Plant Dis. 100:686-695.

Friskop, A., Kinzer, K., McConnell, M., and Liu, Z. 2014. First report of Goss's bacterial leaf blight and wilt of corn caused by Clavibacter michiganensis subsp. nebraskensis in North Dakota. Plant Dis. 98:1739.

Gross, D. C., and Vidaver, A. K. 1979. A selective medium for isolation of Corynebacterium nebraskense from soil and plant parts. Phytopathology 69:82-87.

Hartsook, J. W., Bohnert, M. R., Baitinger, D. J., da Silva Dias, A. P., and Frey, T. J. 2015. Needleless inoculation. U.S. Patent no. 8943746B2.

Howard, R. J., Harding, M. W., Lynn, J., Kawchuk, L. M., and Rasmussen, N. M. 2015. First report of Goss's bacterial wilt and leaf blight on corn caused by Clavibacter michiganensis subsp. nebraskensis in Alberta, Canada. Plant Dis. 99:1034.

Ikley, J. T., Wise, K. A., and Johnson, W. G. 2015. Annual ryegrass (Lolium multiflorum), Johnsongrass (Sorghum halepense), and large crabgrass (Digitaria sanguinalis) are alternative hosts for Clavibacter michiganensis subsp. nebraskensis, causal agent of Goss's wilt of corn. Weed Sci. 63: 901-909.

Ivanoff, S. S. 1933. Stewart's wilt disease of corn, with emphasis on the life history of Phytomonas stewarti in relation to pathogenesis. J. Agric. Res. 47:749-770.

Jackson, T. A., Harveson, R. M., and Vidaver, A. K. 2007. Reemergence of Goss's wilt and blight of corn to the central High Plains. Online. Plant Health Prog. doi.org/10.1094/PHP-2007-0919-01-BR
Korus, K. A. 2011. Evaluating commercially available diagnostic tests for the detection of Clavibacter michiganensis subsp. nebraskensis, cause of Goss's bacterial wilt and leaf blight in corn. M.Sc. Thesis. University of Nebraska.

Korus, K. A., Timmerman, A. D., French-Monar, R. D., and Jackson, T. A. 2011 First report of Goss's bacterial wilt and leaf blight (Clavibacter michiganensis subsp. nebraskensis) of corn in Texas. Plant Dis. 95:73.

Langemeier, C. B., Jackson-Ziems, T. A., and Kruger, G. R. 2014. Four common Setaria species are alternative hosts for Clavibacter michiganensis subsp. nebraskensis, causal agent of Goss's bacterial wilt and blight of corn. Plant Health Prog. doi:10.1094/PHP-RS-12-0160

Langemeier, C. B., Robertson, A. E., Wang, D., Jackson-Ziems, T. A., and Kruger, G. R. 2017. Factors affecting the development and severity of Goss's bacterial wilt and leaf blight of corn, caused by Clavibacter michiganensis subsp. nebraskensis. Plant Dis. 101:54-61.

Malvick, D., Syverson, R., Mollov, D., and Ishimaru, C. A. 2010. Goss's bacterial blight and wilt of corn caused by Clavibacter michiganensis subsp. nebraskensis occurs in Minnesota. Plant Dis. 94:1064.

Michener, P. M., Pataky, J. K., and White, D. G. 2002. Transmission of Erwinia stewartii from plants to kernels and reactions of corn hybrids to Stewart's wilt. Plant Dis. 86:167-172.

Ott, L. 1988. An Introduction to Statistical Methods and Data Analysis, 3rd Ed Merrell Dow Research Institute, Boston.

Rand, F. V., and Cash, L. C. 1933. Bacterial wilt of corn. USDA Tech. Bull. No. 362.

Ruhl, G., Wise, K., Creswell, T., Leonberger, A., and Speers, C. 2009. First report of Goss's bacterial wilt and leaf blight on corn caused by Clavibacter michiganensis subsp. nebraskensis in Indiana. Plant Dis. 93:841.

Schuster, M. L. 1972. Leaf freckles and wilt, a new corn disease. Pages 176-191 in: Proc. $27^{\text {th }}$ Ann. Corn and Sorghum Res. Conf., Washington D.C.

Schuster, M. L. 1975. Leaf freckles and wilt of corn incited by Corynebacterium nebraskense. Schuster, Hoff, Mandel, Lazar, 1972. Neb. Agric. Exp. Stn. Res. Bull. 270.

Shepherd, L. M. 1999. Detection and transmission of Clavibacter michiganensis subsp. nebraskensis from corn. M.Sc. Thesis. Iowa State University, Ames, IA.

Shepherd, L. M., Block, C. C., and Vidaver, A. K. 2017. Detection of Clavibacter michiganensis subsp. nebraskensis in maize seeds. Pages 39-43 in: Detection of Plant-Pathogenic Bacteria in Seed and Other Planting Material, 2nd Ed. M. Fatmi, R. Walcott, and N. Schaad, eds. American Phytopathological Society, St. Paul, MN.

Singh, R., Hollier, C., Burks, T., and Frazier, R. 2015. First report of Goss's wilt of corn caused by Clavibacter michiganensis subsp. nebraskensis in Louisiana. Plant Dis. 99:1268.

Smidt, M., and Vidaver, A. 1986. Population dynamics of Clavibacter michiganense subsp. nebraskense in field-grown dent corn and popcorn. Plant Dis. 70:1031-1036.

Steel, R. G. D., and Torrie, J. H. 1980. Principles and Procedures of Statistics: A Biometrical Approach, 2nd Ed. McGraw-Hill, New York.

Wysong, D. S., Doupnik, B., and Lane, L. 1981. Goss's wilt and corn lethal necrosis Can they become a major problem? Pages 104-130 in: Proc. $36^{\text {th }}$ Annu. Corn Sorghum Res. Conf. American Seed Trade Assoc., Washington, D.C.

Wysong, D. S., Vidaver, A. K., Stevens, H., and Stenberg, D. 1973. Occurrence and spread of an undescribed species of Corynebacterium, pathogenic on corn in the western corn belt. Plant Dis. Rep. 57:291-294. 